\title{
A NUMERICAL INVESTIGATION OF NANOFLUID FLOW IN RECTANGULAR FINNED MICROCHANNEL
}

\author{
Halime ÇELIK** and Nezaket PARLAK** \\ *Sakarya Uygulamalı Bilimler Üniversitesi Teknoloji Fakültesi Makine Mühendisliği Bölümü, \\ 54050 Serdivan, Sakarya, halimeclik@ sakarya.edu.tr, ORCID: 0000-0002-0279-046X \\ **Sakarya Üniversitesi Mühendislik Fakültesi Makine Mühendisliği Bölümü, \\ 54050 Serdivan, Sakarya, naydemir@ sakarya.edu.tr, ORCID: 0000-0002-8469-2192
}

(Geliş Tarihi: 15.06.2020, Kabul Tarihi: 29.01.2021)

\begin{abstract}
A numerical study and parameter optimization was carried out to find the effects of geometric parameters and nanofluid concentration on heat transfer and pressure drop characteristics of a finned microchannel. Six dual rectangular fins with different layouts were placed in a single microchannel having rectangular cross section. The hydraulic diameter of the microchannel was kept constant and the length, width and angle of fin between the horizontal axes were determined as parameters. The water was selected as base fluid and the effect of volumetric concentration of nanofluids $\left(\mathrm{Al}_{2} \mathrm{O}_{3}(0 \%\right.$ to $\left.0.4 \%)\right)$ on fluid flow and heat transfer were investigated. Volumetric concentration of nanofluids and fin geometry was optimized with Response Surface Optimization method for the levels of different parameters and Computational Fluid Dynamics (CFD) analyses (ANSYS Fluent 18) was performed at different flow rates. CFD results calculated for the optimum finned microchannel were compared to those of the straight (finless) microchannel. As a result of the study, nanofluid concentration increment and fins improved the heat transfer and increased the pressure drop.
\end{abstract}

Keywords: Microchannel, Nanofluid, Fin, CFD Analysis, Optimization

\section{KANATÇIKLI DİKDÖRTGEN KESITTLİ MİKROKANALDA NANOAKIŞKAN AKIŞININ SAYISAL İNCELENMESI}

Özet: Kanatçıklı bir mikrokanalın 1sı transferi ve basınç düşšüü özellikleri üzerindeki geometrik parametrelerin ve nanoakışkan konsantrasyonunun etkilerini bulmak için sayısal bir çalışma gerçekleştirilmiştir. Dikdörtgen kesite sahip tek bir mikrokanala farklı yerleşimlere sahip altı adet ikili dikdörtgen kanat yerleştirildi. Mikrokanalın hidrolik çapı sabit tutularak yatay eksenler arasındaki kanat uzunluğu, genişliği ve açısı parametre olarak belirlendi. Baz akışkan olarak su seçilmiş ve hacimsel nanoakışkan konsantrasyonunun $\left(\mathrm{Al}_{2} \mathrm{O}_{3}(\% \quad-\%\right.$ 0.4)) akış ve 1 sı transferi üzerindeki etkisi araştırılmıştır. Nanoakışkanların hacimsel konsantrasyonu ve kanatçık geometrisi, farklı parametrelerin seviyeleri için Yanıt Yüzey Optimizasyon (Response Surface Optimization) yöntemi ile optimize edilmiş ve farklı akış hızlarında Hesaplamalı Akışkanlar Dinamiği (CFD) analizleri (ANSYS Fluent 18) gerçekleştirilmiştir. Optimum kanatlı mikrokanal için hesaplanan CFD sonuçları, düz (kanatsız) mikrokanalınkilerle karşılaştırıldı. Çalışma sonucunda nanoakışkan konsantrasyon artışı ve kanatçıklar 1sı transferini iyileştirmiş ve basınç düşüuşünü artırmıştır.

Anahtar kelimeler: Mikrokanal, Nanoakışkan, kanatçık, CFD analizi, Optimizasyon

\section{NOMENCLATURE}

$L \quad$ Microchannel length (mm)

$W$ Microchannel Width (mm)

$H$ Microchannel Height ( $\mathrm{mm})$

$A$ Surface area $\left(\mathrm{m}^{2}\right)$

$c_{p}$ Specific heat capacity at constant pressure $\left(\mathrm{Jkg}^{-1} \mathrm{~K}^{-1}\right)$

$D$ Hydraulic diameter (m)

$f$ Darcy friction factor

$h$ Heat transfer coefficient $\left(\mathrm{W} \mathrm{m}^{-2} \mathrm{~K}^{-1}\right)$

$k$ Thermal conductivity $\left(\mathrm{W} \mathrm{m}^{-1} \mathrm{~K}^{-1}\right.$ )

$L \quad$ Microchannel length (m)

$\dot{m}$ Mass flow rate $\left(\mathrm{kg} \mathrm{s}^{-1}\right)$
$P$ Pressure $(\mathrm{Pa})$

$\mathrm{Nu}$ Nusselt number

Pr Prandtl number

$R e$ Reynolds number

$T$ Temperature (K)

$V$ Velocity $\left(\mathrm{m} \mathrm{s}^{-1}\right)$

Greek symbols

$\varphi$ Volume fraction (\%)

$\mu$ Dynamic viscosity (Pa s)

$\rho$ Density (kg m-3)

$\alpha$ Thermal diffusion $\left(\mathrm{m}^{2} \mathrm{~s}^{-1}\right)$ 


\author{
Subscripts \\ $n f$ nanofluids \\ bf basefluid \\ $p$ particles \\ $f$ fluid
}

\section{INTRODUCTION}

Today, research on nanofluids to improve heat transfer is rapidly ongoing. Nanofluids are suspensions formed by adding nanometer-sized $(<100 \mathrm{~nm})$ solid particles of copper, aluminum, silver, gold, silicon dioxide to a base fluid such as water, ethylene and propylene glycol. The purpose of using nanofluids is to passively increase the heat transfer by obtaining fluids with better thermal properties than conventional fluids.

Another passive technique of heat transfer enhancement is to increase the heat transfer surface by means of fins, rods, protrusions. Expanded or extended surfaces are widely used in many areas such as spacecraft, airplanes, cooling, heating, air conditioning, chemical and petrochemical industries, electronics, and industrial furnaces, nuclear, solar and traditional power plants where heat transfer occurs. The enlarged surfaces can be cast in a variety of geometric shapes with the main surface in the form of fins and protrusions, or they may be attached to the main body separately by means of engagement, screwing, welding. In practice, it is seen that rectangular and circular (pipe) fins are mostly used (DeWitt and Incropera, 2002). The use of micro-scale systems in flow applications, creating a larger surface area in a small volume, and providing the opportunity to work in small areas have provided many advantages. These miniature devices with microchannels are known to be used in various fields such as environment, automotive, process control, metrology, defense, aviation, aerospace, pharmaceuticals, chemistry, medicine and biology. Triangular, square and circular fins are placed inside a duct to increase the heat transfer in a macro-scale duct. These fins both act as a vortex generator and increase the surface area, allowing the heat flux to dissipate faster. On the other hand, fins increase the drag coefficient in the channel and affect the pressure drop negatively.

In micro-scale channels, single-phase flow and heat transfer are of interest for cooling electronic and similar devices due to the small boundary layer thickness, but the high pressure drop constitutes an obstacle to its use as an efficient cooling method. For this reason, micro-scale studies have focused on finding the optimum geometry in a certain working pressure range. Within the scope of this study, the literature survey includes finned microchannels studies and studies in which nanofluids are used as fluids in microchannels. Considering the studies on finned microchannels, it is seen that there is a crucial lack of experimental data due to insufficient of precision manufacturing and measurement techniques. (Ma et al., 2010) have investigated the effect of fins (vortex generators) placed longitudinally in rectangular channels with hydraulic diameter of $5.58 \mathrm{~mm}$ on flow and heat transfer. Water has been used as a working fluid. They have observed an increase of $11.4 \%$ in pressure drop and $101 \%$ in heat transfer underwater laminar flow conditions $(310<\operatorname{Re}<4220)$. (Liu et al., 2011) have experimentally studied the effect of fins placed in a rectangular channel with hydraulic diameter of $187.5 \mathrm{~mm}$ on the single phase water flow and heat transfer for the range of $170<\operatorname{Re}<1200$. They have reported that heat transfer increased by $21 \%$ in the laminar flow conditions and $90 \%$ under turbulent flow conditions thanks to the fins placed in the channel. On the other hand, the pressure drop increased by $83 \%$ in laminar flow conditions and by $169 \%$ under turbulent flow conditions. The average uncertainties caused by experimental apparatuses in determining $f$ and $\mathrm{Nu}$ for tests are found to be $5.86 \%$ and $19.6 \%$, respectively. They also stated that the transition from laminar to turbulent flow occurs earlier in finned rectangular microchannels compared to the straight (finless) rectangular microchannel. (Chen et al., 2014) have conducted an experimental study using water as a fluid to investigate flow and heat transfer in finned rectangular microchannels. The experiments have been carried out under constant wall temperature boundary conditions for the Reynolds numbers ranging from 350 to 1500. The hydraulic diameters of the rectangular microchannels were reported to be $160 \mu \mathrm{m}$ and $188 \mu \mathrm{m}$ with an aspect ratio of 0.25 and 0.0667 , respectively. The results have shown that the pressure losses increased by $40 \%$ and heat transfer performance increased by $12.3 \%$ in finned channels. The maximum uncertainties of friction factor and Nusselt number are 5.78 and $20.98 \%$ respectively. In addition, it has been reported that the critical Reynolds number decreases as the number of fins (vortex generators) placed inside the channel increases. Experiments have shown that the fins placed in the channel increase the heat transfer and pressure drop and decrease the critical Re number. (Ugurlubilek, 2014) has numerically investigated convective heat transfer and flow in a channel with two semi-circular obstacles under uniform wall temperature boundary conditions. The conservation equations have been solved by Ansys Fluent and Nusselt numbers and friction coefficients have been presented comparatively for the channel with and without obstacles. They have reported that an improvement of $47 \%$ in heat transfer. (Ebrahimi et al., 2015) have numerically investigated the single phase laminar flow and heat transfer in rectangular microchannels with vortex generators (fin). Numerical results have been compared with the available experimental data and comparison have showed to be in a good agreement. They have also stated that the Nusselt number increased by $25 \%$ in the Reynolds range of 100 to 1100 , while the friction factor increased by about $30 \%$ in the finned channels. (Lelea, 2011) has investigated the effect of particle diameter on the flow and heat transfer of $\mathrm{Al}_{2} \mathrm{O}_{3}$ /water nanofluid in a microchannel heat exchanger numerically. Nanofluids was encountered with $\mathrm{Al}_{2} \mathrm{O}_{3}$ nanoparticles with diameters of 13,28 and 47 $\mu \mathrm{m}$ at different volumetric concentrations (from $1 \%$ to $9 \%$ ). Results revealed that heat transfer augmentation decreases as the particle's diameter increases and for 
higher pumping power and cooling case it remains constant as long as particle's diameter is $d p>28 \mathrm{~nm}$. In addition, as the volume concentration and Reynolds numbers are increased, heat transfer have increased. The improvement of heat transfer in a 3D microchannel cooler using nano fluids has been studied in a numerical study (Hung et al., 2012). Results have shown that the use of $\mathrm{Al}_{2} \mathrm{O}_{3} /$ water nanofluids in the microchannel cooling system can improve heat transfer. The effectiveness of $\mathrm{Al}_{2} \mathrm{O}_{3}$ /water nanofluids in improving the overall performance of the microchannel refrigerant has been numerically investigated using the SIMPLEC algorithm by (Wu et al., 2016). Results have shown that the effectiveness of nanofluid on improving the heat management capability of MCHS is related to the given pumping power of electronic device and a reduction of thermal resistance could be gained only when the given pumping power is high. (Ebrahimi et al., 2016) have performed three-dimensional simulations using a singlephase flow model. Their results show that nanofluids increase the pressure drop by 3.5 to $16 \%$ compared to pure water.

When studies on nanofluids are reviewed, it was seen that a lot of articles were published in the open literaure. In general, experimental and numerical studies on nanofluids have showed that nanoparticle type (Lelea, 2011; Hung, et al., 2012; Karimzadehkhouei, 2017), nanoparticle size (Hu et al., 2011) and volumetric concentration (Lelea, 2011; Hung et al., 2012; Zarringhalam et al., 2016; Khaleduzzaman et al., 2017), mass flow rate (Lelea, 2011; Khaleduzzaman et al., 2017) have important effects on flow and heat transfer. (Sohel et al., 2014) have conducted an experimental study with $\mathrm{Al}_{2} \mathrm{O}_{3}$ /water nanofluids in a minichannel heat sink for electronics cooling. In experiments, $\mathrm{Al}_{2} \mathrm{O}_{3} /$ water nanofluids are made in four different concentration i.e. 0.10 Vol. \%, 0.15 Vol. \%, 0.20 Vol. \% and 0.25 Vol. \% and the Reynolds number ranged from 395 to 989 . The mini channels in the cooler have a rectangular section with hydraulic diameter of $0.615 \mathrm{~mm}$. Nusselts numbers were between 3.3 and 3.8. The results showed that the heat transfer coefficient increased by $18 \%$ and also $15.72 \%$ less thermal resistance at 0.25 vol. $\%$ compared to the distilled water. (Sivakumar et al., 2016) have conducted experimental studies with $\mathrm{Al}_{2} \mathrm{O}_{3} /$ water nanofluids in a microchannel heat sink. Nu numbers for $0.3 \%$ volumetric concentration in experiments ranged from 0.57 to 3.01 for $107<\operatorname{Re}<622$. (Ho et al., 2019) have conducted an experimental study on the convection heat transfer of $\mathrm{Al}_{2} \mathrm{O}_{3} /$ water nanofluids with $2-8 \mathrm{wt} \%$ concentrations in a parallel minichannel heat sink. Findings showed that the maximum pressure drop ratio (nanofluid to pure water) of 1.41 is observed by flowing nanofluid with $8 \%$ nanoparticle concentration for $\mathrm{Re}=258$ and the maximum heat transfer effectiveness is achieved 1.4 for $R e=1549$. Two general numerical methods are used to simulate single-phase nanofluid flow and heat transfer in macro / micro channels: single-phase methods and two-phase methods. The former includes both homogeneous and dispersion models, while the second includes Eulerian-Eulerian (fluid volume, mixing and Eulerian) and Eulerian-Lagrangian models and Discrete Phase Model (Liang and Mudawar, 2019).

In recent years, it has been observed that numerical studies are conducted using a single phase nanofluids models or a two phase models. (Arshi Banu et al., 2020) performed a numerical study on the hydrodynamic and thermal behavior of the micro-pin-fin heat exchanger using a single phase model to investigate the pressure drop variations and heat transfer rate using $\mathrm{Al}_{2} \mathrm{O}_{3} /$ water and $\mathrm{CuO}$-water nanofluids for different volume fraction. On the other hand, a numerical investigation is conducted by implementing a two-phase model based on the mixture theory with the aim of assessing the attributes associated with the thermohydraulic performance of the $\mathrm{Cu}$ /water nanofluid through a square channel (Bahiraei et al., 2019). Moreover, using single and two phase models thermal and hydraulic performances of minichannel heat sink were studied by (Saeed and Kim, 2018), numerically. Comparison of single-phase model with the experimental results revealed that single phase model under-predicted the values of convective heat transfer coefficient. Maximum disagreement between single phase numerical model and experimental results was found to be $5.02 \%$ against volume concentration of $1.0 \%$. On the other hand, two-phase model overpredicted the convective heat transfer coefficient values. Maximum disagreement found between numerical twophase and experimental values are $5.01 \%$ respectively. (Ghasemi et al., 2017) have simulated laminar forced convection heat transfer in the rectangular and circular minichannel heat sinks with nanofluid for various volume fraction of $\mathrm{CuO}$ nanoparticles. Single phase and Two-phase methods were utilized for solving the incompressible, three dimensional and steady state problem with particle volume fraction range between $0.25 \%$ and $0.75 \%$. Even if they stated that the double phase model results were more accurate than the single phase model results; maximum and minimum disagreement between experimental and single-phase numerical results for $1 \%$ volume concentration was reported to be $1.3 \%$ and $3.5 \%$, respectively. On the other hand, it has been reported that the maximum and minimum difference between the experimental and the numerical two-phase model results are $0.2 \%$ and $1.9 \%$, respectively. The maximum deviation between the findings obtained in both studies (Saeed and Kim, 2018; Ghasemi et al., 2017) is around 5\%. Moreover, (Turkyilmazoglu, 2019) concluded that two phase model is in compliant with the single phase in the special case of his problem.

Considering the methods of improving heat transfer, studies on nanofluids are noteworthy. It achieves a fluid with better thermal properties than conventional fluids and increases the heat transfer passively. Another passive heat transfer enhancement method is to increase the heat transfer surface by means of fins, rods, protrusions. When the literature is reviewed, single-phase laminar flow and heat transfer in rectangular microchannels have been investigated by (Ugurlubilek, 2014) and (Ebrahimi et al., 2015), (Lelea, 2011) and (Hung et al., 2012) have 
examined the effect of $\mathrm{Al}_{2} \mathrm{O}_{3}$ /water nanofluids on heat transfer in finned microchannels, numerically. As can be seen from the literature, parametric optimization studies have not been conducted, yet. In the literature, there are studies showing that the fins placed in the channel increase the heat transfer and increase the pressure drop. In addition, there is a need for geometric studies that provide optimum pressure drop and heat transfer. For this reason, it is very important to make a single phase flow and heat transfer characteristic by performing a geometric optimization study on micro scale. The current study has two main objectives. The first is to find the best/optimum finned microchannel geometry, which gives the highest heat transfer and the lowest pressure drop. The second is to perform CFD simulations of $\mathrm{Al}_{2} \mathrm{O}_{3} /$ water nanofluids in the optimum finned microchannel for velocities in the range of 1 to $7 \mathrm{~m} / \mathrm{s}$. Thus, 6 pairs of rectangular fins were placed in a single microchannel of rectangular cross-section. By keeping the hydraulic diameter of the microchannel constant, the length, width, angle of the fins and volumetric concentration of nanofluids were determined as parameters. Using water as the base fluid, the flow and heat transfer properties of the volumetric concentration of $\mathrm{Al}_{2} \mathrm{O}_{3}$ /water nanofluids (volume fractions between 0 and $0.4 \%$ ) were investigated. Geometric parameters were optimized by Response Surface Optimization method and volumetric concentrations were determined with optimum geometry and analyzed at different flow rates. Computational Fluid Dynamics (CFD) analysis was performed with Ansys Fluent 18 commercial software. In a finned microchannel, the nanofluid flow was investigated by CFD analysis, which are under constant temperature thermal conditions.

\section{PARAMETRIC DESIGN AND OPTIMIZATION}

ANSYS enables extensive design exploration and optimization in Workbench environment. Default (2nd order polynomial) Response Surface Optimization method has been selected for the optimization. Response surface methodology (RSM) focuses on input-output relationships and it an efficient way to get the variation of a given performance with respect to input parameters. Optimization studies are carried out by following the steps, shown in Fig. 1. First, the parameters affecting the nanofluids flow and heat transfer in the finned microchannel have been idendified. Then, boundary conditions are set and CFD simulations are performed. The parameters that affect the optimization problem and their levels are defined and CFD-based optimization calculations are made.

\section{Microchannel Geometry and Parameters}

An optimization study has been performed in order to find the finned microchannel geometry which gives the highest heat transfer rate and the lowest pressure drop. The height of the rectangular microchannel has been indicated by $\mathrm{H}$, the width by $\mathrm{W}$, and the length of the microchannel by L. The geometry details of the microchannel have been given in Table 1 .
In the microchannel, width, length and the angle of the fins have been taken as parameters. In Fig. 2, the designed fins geometry. The parameters and their constraints (upper and lower bound) and the targets in the optimization are given in Table 2 .

The fins which are in the shape of a rectangular prism and whose geometric parameters have been identical to each other have been positioned adjacent to the lower wall, mutually along the channel. There have been totally 12 fins in the microchannel. Here the optimization parameters of the angle [P2], width [P3] and length [P4] of the fins have been shown in Fig. $2 b$.

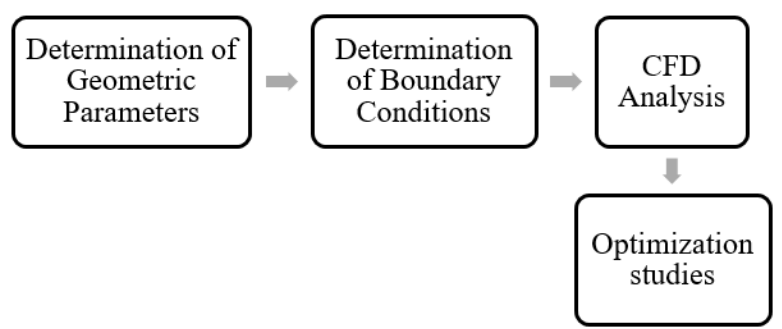

Figure 1. CFD optimization study scheme

Table 1. Microchannel Geometry

\begin{tabular}{|l|l|}
\hline Microchannel Geometry & {$[\mathbf{m m}]$} \\
\hline Microchannel Width,W & 0.35 \\
\hline Microchannel Height, H & 0.1 \\
\hline Microchannel Length, L & 10 \\
\hline
\end{tabular}

Table 2. Parameters and constraints

\begin{tabular}{|c|l|l|l|}
\hline Target & \multicolumn{3}{|c|}{ Constraints } \\
\hline $\begin{array}{c}\text { To maximize } \\
\text { the heat } \\
\text { transfer rate }\end{array}$ & Parameters & $\begin{array}{l}\text { Lower } \\
\text { bound }\end{array}$ & $\begin{array}{l}\text { Upper } \\
\text { bound }\end{array}$ \\
\cline { 2 - 4 } $\begin{array}{c}\text { To minimize } \\
\text { the pressure } \\
\text { drop }\end{array}$ & P2 - Fin Angle $\left(^{\circ}\right)$ & 30 & 60 \\
\cline { 2 - 4 } & P3-Fin Thickness[mm] & 0.03 & 0.05 \\
\cline { 2 - 4 } & P4 -Fin Length [mm] & 0.05 & 0.15 \\
\cline { 2 - 4 } & Volume flow rate [\%] & 0 & 0.4 \\
\hline
\end{tabular}

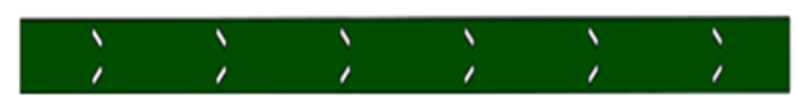

(a)

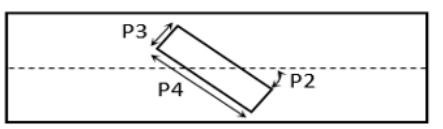

(b)

Figure 2. a) Top view of finned microchannel b) Fin parameters

Values of geometric constraint parameters and nanofluids volume flow rates (lower and upper band) have been defined in the Fluent Parameter set section 
given in the Table 2. Water has been taken as the base fluid and alumina have been preferred as nano particles. It is assumed that the $\mathrm{Al}_{2} \mathrm{O}_{3}$ nanoparticles have a nearspherical shape, $99.8 \%$ purity, specific surface area between 85 and $115\left(\mathrm{~m}^{2} / \mathrm{g}\right)$ and particle sizes of 13 nanometers. The properties of water and nanoparticles have been given in Table 3. The correlations for calculating the thermophysical properties of the nanofluid are given in the Table 4 . The equations given in Table 4 are defined in the parameter set section, in order to calculate the thermophysical properties according to the volumetric flow rates.

Table 3. Properties of water $\left(\mathrm{H}_{2} \mathrm{O}\right)$ and nanoparticles

\begin{tabular}{|l|l|l|l|l|}
\hline $\begin{array}{l}\text { Fluid and/or } \\
\text { nanoparticles }\end{array}$ & $\begin{array}{l}\rho \\
\left(\mathrm{kg} / \mathrm{m}^{3}\right)\end{array}$ & $\begin{array}{l}\mathrm{c}_{\mathrm{p}} \\
(\mathrm{j} / \mathrm{kgK})\end{array}$ & $\begin{array}{l}\mathrm{k} \\
(\mathrm{W} / \mathrm{mK})\end{array}$ & $\begin{array}{l}\mu \\
(\mathrm{Pa} . \mathrm{s})\end{array}$ \\
\hline $\mathrm{H}_{2} \mathrm{O}$ & 998.2 & 4175.78 & 0.601 & $8.8325 \times 10^{-4}$ \\
\hline $\mathrm{Al}_{2} \mathrm{O}_{3}$ & 3890 & 778 & 46 & - \\
\hline
\end{tabular}

The highest heat transfer and lowest pressure drop have been determined as target in optimization process. When the optimization process is completed, the candidate values of parameters are suggested by DesignXplorer. The candidate values are presented with stars, crosses and dashes where three stars mean that the parameter meets all the specified objectives. In this study, candidate points with 3 stars achieving both targets have been considered as optimum values. Afterwards, CFD simulations have been performed at different flow rates using the optimum model. In the analysis, the flow was assumed to be single phase, laminar, incompressible and fluid was Newtonian. The fluid velocity was varied from 1 to $7 \mathrm{~m} / \mathrm{s}$.

\section{COMPUTATIONAL FLUID DYNAMICS (CFD) ANALYSIS}

\section{CFD Analysis For Optimum Finned Microchannel} With $\mathrm{Al}_{2} \mathrm{O}_{3} /$ Water Nanofluids

In this analysis, $\mathrm{Al}_{2} \mathrm{O}_{3}$ /water was used as the fluid and only the bottom surface of the microchannel was assumed to be constant temperature at 358 . The nanofluid entered the microchannel with temperature and velocity of $298 \mathrm{~K}$ and $1 \mathrm{~m} / \mathrm{s}$. The outlet pressure was taken as 0 $\mathrm{Pa}$ and the inlet pressure was assumed as the pressure drop. The three dimesional modeling was created in the ANSYS Workbench interface; boundary conditions, conservation equations were solved in Fluent interface. A structured non-uniform mesh spacing distribution was used to solve the computational domain. Triangular elements were chosen forming mesh. Structured grid of finned microchannel was shown in Fig.3.

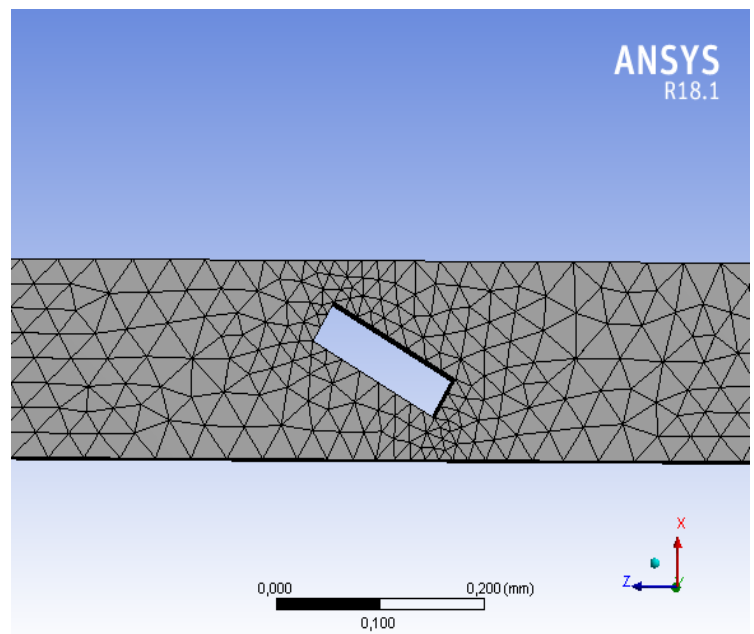

Figure 3. Grid structure of finned microchannel model

\section{Grid independence analysis}

In the analysis, several different grid densities have been tested to provide that numerical results are grid independent. Table 5 shows numerical results obtained from grid independence analysis. Percentage deviation has been calculated by $\left(\frac{f_{2}-f_{1}}{f_{1}} \times 100\right)$. The number of elements ranged from $1.7 \mathrm{E}+6$ to $3.4 \mathrm{E}+6$ and the percentage deviations between the results remained below 5\%. The deviations for outlet temperature and pressure drop obtained in the analysis after 2 million elements were below 1\%. 3.1 million elements were found acceptable with a deviation of $0.8 \%$. In addition, the solution was considered to converge and the relative residuals of contunity, momentum and energy equations were less than 0.0001 .

Table 4. The correlations of thermophysical properties of $\mathrm{Al}_{2} \mathrm{O}_{3} /$ water nanofluids

\begin{tabular}{|l|c|l|}
\hline Thermophysical properties & Correlations & Models [References] \\
\hline$\rho\left(\mathrm{kg} / \mathrm{m}^{3}\right)$ & $\rho_{n f}=\rho_{n p} \varphi+\rho_{b f}(1-\varphi)$ & (Cho and Pak, 1998) \\
\hline $\mathrm{cp}(\mathrm{j} / \mathrm{kgK})$ & $\rho_{n f} c_{n f}=\rho_{n p} c_{n p} \varphi+\rho_{b f} c_{b f}(1-\varphi)$ & (Roetzel and Xuan, 2000) \\
\hline $\mathrm{k}(\mathrm{W} / \mathrm{mK})$ & $\frac{k_{e f f}}{k f}=\frac{k_{p}+2 k_{f}-2 \varphi\left(k_{f}-k_{p}\right)(1+\eta)^{3}}{k_{p}+2 k_{f}-\varphi\left(k_{f}-k_{p}\right)(1+\eta)^{3}}$ & (Choi and Yu, 2003) \\
\hline$\mu(\mathrm{Pa} . \mathrm{s})$ & $\frac{\mu_{n f}}{\mu_{b f}}=(1-\varphi)^{-2.5}$ & (Brinkman, 1952) \\
\hline
\end{tabular}

Table 5. Grid independence test results

\begin{tabular}{|l|l|l|l|l|l|}
\hline Cases & Grid numbers & $\begin{array}{l}\text { Pressure drop } \\
{[\mathrm{kPa}]}\end{array}$ & $\begin{array}{l}\text { Percentage } \\
\text { Deviations [\%] }\end{array}$ & $\begin{array}{l}\text { Outlet temperature } \\
{[\mathrm{K}]}\end{array}$ & $\begin{array}{l}\text { Percentage } \\
\text { Deviations[\%] }\end{array}$ \\
\hline Case 1 & $1.7 \mathrm{E}+6$ & 35242.63 & - & 329.36 & - \\
\hline Case 2 & $2.2 \mathrm{E}+6$ & 33781.76 & 4.14 & 326.72 & 0.8 \\
\hline Case 3 & $3.1 \mathrm{E}+6$ & 33509.82 & 0.80 & 326.68 & 0.01 \\
\hline
\end{tabular}




\section{OPTIMIZATION RESULTS}

\section{Optimization Results For Finned Microchannel $\mathrm{Al}_{2} \mathrm{O}_{3} /$ Water}

The optimum geometric parameters that provide the lowest pressure drop and the highest heat transfer were determined by CFD based parametric optimization. The optimum parameters obtained were given in Table 6 .

Table 6. Finned Microchannel (FMC) $\mathrm{Al}_{2} \mathrm{O}_{3} /$ Water Optimization Studies

\begin{tabular}{|l|l|}
\hline P2 - Fin angle $\left[{ }^{\circ}\right]$ & 34.058 \\
\hline P3 - Fin thickness $[\mu \mathrm{m}$ & 36.5 \\
\hline P4 - Fin Length $[\mu \mathrm{m}]$ & 50.6 \\
\hline Volumetric concentration $[\%]$ & 0.392 \\
\hline Outlet temperature $[\mathrm{K}]$ & 349.05 \\
\hline Pressure drop $[\mathrm{kPa}]$ & 95.93 \\
\hline Heat transfer $[\mathrm{W}]$ & 3.2592 \\
\hline
\end{tabular}

The effects of parameters on the output temperature and pressure drop results were examined in detail. In order to show the effects of geometric parameters, additional simulations were performed three different levels of each geometric parameter by keeping the volumetric concentration constant. Effect of fin angle on results was shown in Fig. 4. The fin angle was changed from 30 to $60^{\circ}$. As a result of the optimization, the optimum fin angle was $34^{\circ}$. The increase of the fin angle increased the inlet pressure and outlet temperature and it led to a $60 \%$ increase in pressure drop, as shown in Fig 2. Since an increase in angle of fin will decrease the cross section through which the fluid passes, it affects the pressure drop significantly. On the other hand, it did not significantly affect the outlet temperature.

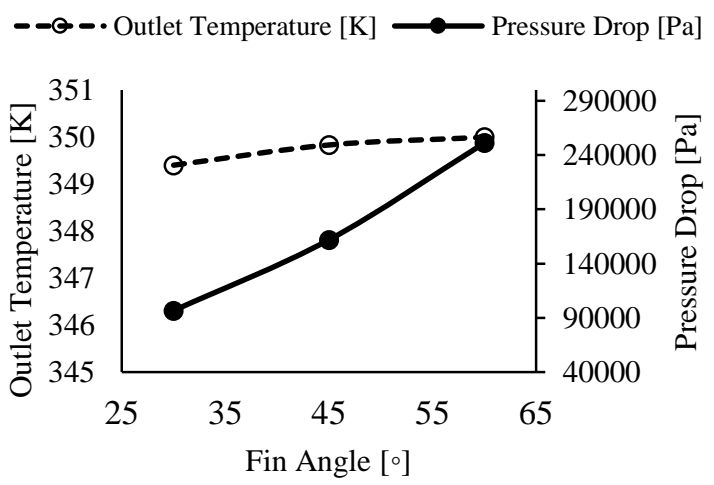

Figure 4. Effect of fin angle on results

In the calculations, the fin thickness was changed from 0.03 to $0.05 \mathrm{~mm}$, shown in Fig. 5. The optimal fin thickness was calculated as $0.03649 \mathrm{~mm}$. The increase of the fin thickness caused a change in the outlet temperature of less than $1 \%$. The thickness of the fin was increased from 0.3 value to 0.05 while the inlet pressure increased. Similarly, the change in pressure drop remained below $1 \%$.

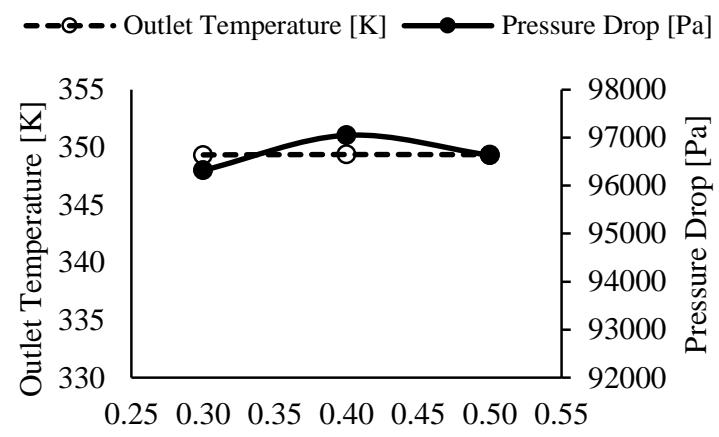

Fin Thickness $[\mathrm{mm}]$

Figure 5. Effect of fin thickness on results

Effect of fin length on results was shown in Fig. 6. The fin length was changed to $0.05,0.1$ and $0.15 \mathrm{~mm}$. Increased fin length increased inlet pressure and outlet temperature by $1 \%$. The fin length was found to have no effect on the results for these $0.05 \mathrm{~mm}$ to $0.15 \mathrm{~mm}$ values.

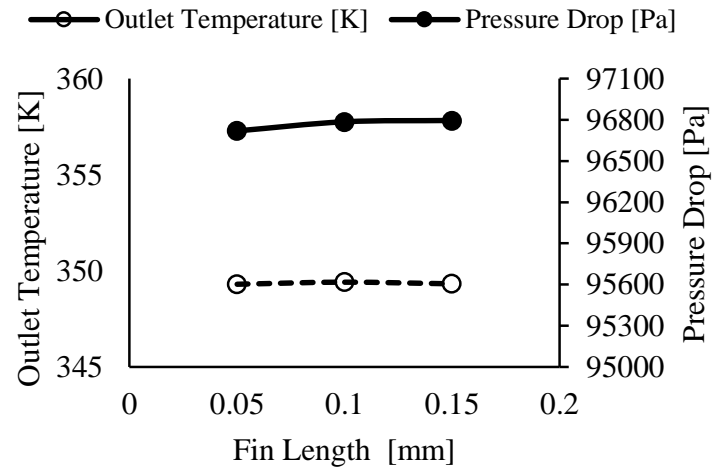

Figure 6. Effect of fin length on results

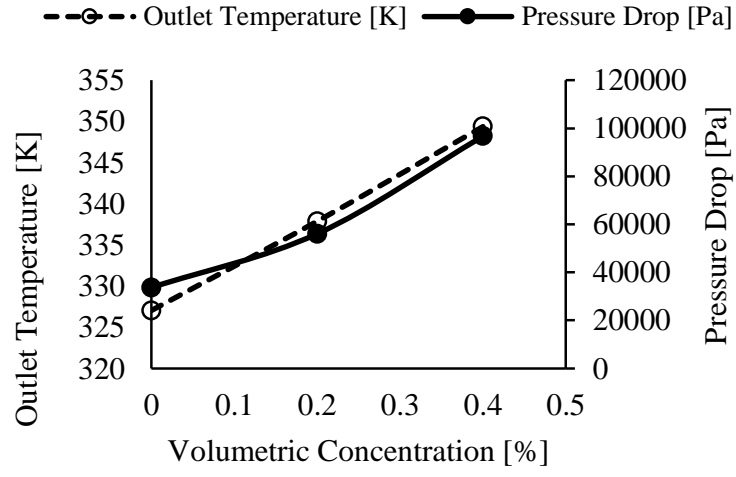

Figure 7. Effect of volumetric concentration on results

The volumetric concentrations of $\mathrm{Al}_{2} \mathrm{O}_{3}$ /water nanofluids were varied from $0 \%$ to $0.4 \%$. as shown in Fig. 7 . Optimal volumetric concentration value was found to be 0.39. As expected, the increase in volumetric concentration led to an increase in pressure drop and outlet temperature. With increasing volumetric concentration, the outlet temperature increased from 327 $\mathrm{K}$ to $349 \mathrm{~K}$. However, the increase in volumetric concentration also caused the pressure drop to increase 
significantly. Similarly, there were studies showing that nanofluids provided better heat transfer from water with increasing volumetric concentration, however, an increase in pressure drop (Lelea, 2011; Ebrahimi et al., 2016).

\section{CFD RESULTS}

\section{CFD Results of Optimum Channel}

CFD simulations of the nanofluids flow of the optimum finned microchannel have been performed in the range of 1 to $7 \mathrm{~m} / \mathrm{s}$. Figs. 8 and 9 . show velocity vectors and temperature changes around the fin in the microchannel. The flow characteristics of the nanofluid in the finned microchannel is shown in Fig. 8. In the laminar flow, fluid layers move in straight lines, and the flow continues without eddies and swirls. Then flow changes direction when it encounters fins. The fins appear to cause turbulence under laminar flow conditions, resulting in flow rates ranging from 1 to $3.73 \mathrm{~m} / \mathrm{s}$. Since fins narrow the flow cross-section, it has been found the maximum flow velocity increases up to $3.73 \mathrm{~m} / \mathrm{s}$.

At higher Reynolds numbers, when an obstacle is placed in front of the flow, the fluid mixes more vigorously, covering longer distances. In this study, it was observed that the fins placed in the microchannel narrowed the cross-sectional area and caused instantaneous velocity increases. It was found that behind the fins, the curl of the velocity fields were formed. No vortex formation in front of fins was observed. The low flow rate also has an effect here. Sequentially placed fins allow the liquid to mix in the microchannel while at the same time causing heat transfer from the hot bottom wall. In this way, the liquid contacts the fin, which is warmer than the liquid.

The bottom wall is cooled more effectively by the nanofluids flow. Fig. 9 shows the temperature distribution around the fin located close to the outlet. The fins also cause an increase in heat transfer surface area and thus an increase in convective heat transfer. In the analysis, the bottom wall was set at a constant temperature, $358 \mathrm{~K}$.

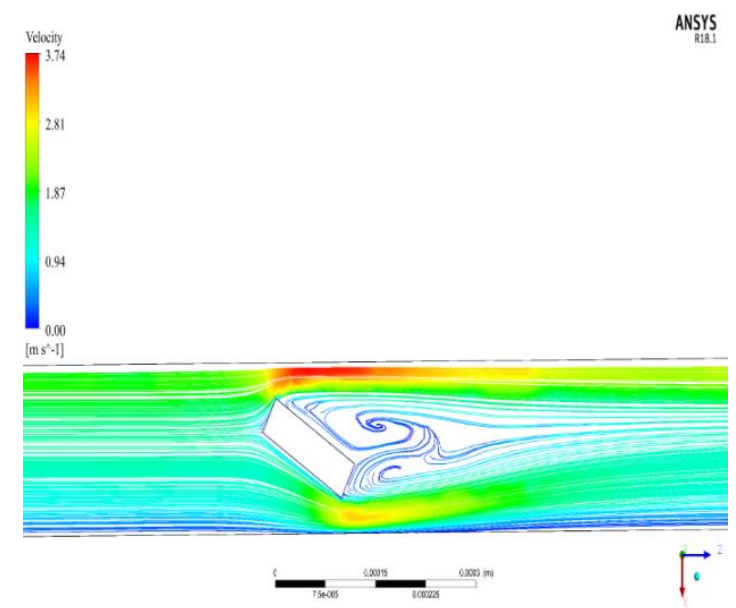

Figure 8. Finned Microchannel (FMC) $\mathrm{Al}_{2} \mathrm{O}_{3} /$ Water CFD Analysis; Velocity zones

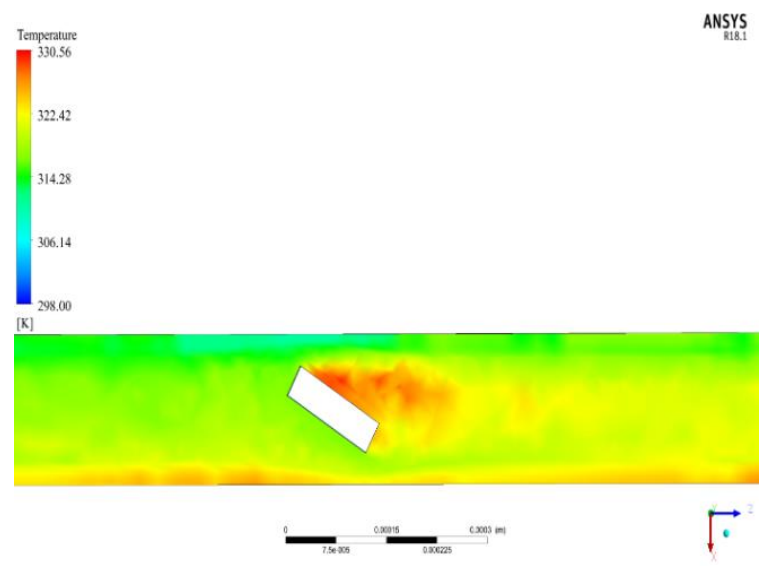

Figure 9. Finned Microchannel (FMC) $\mathrm{Al}_{2} \mathrm{O}_{3} /$ Water CFD Analysis; Temperature zones around the fins

CFD simulations were repeated for different volumetric concentrations of nanofluids at a fluid velocity of $4 \mathrm{~m} / \mathrm{s}$ in the optimum finned channel. Figure 10 shows the effect of volumetric concentration of nanofluids on heat transfer coefficient and thermal conductivity in the optimum finned channel. It has been observed that as the volumetric concentration increases, the heat transfer coefficient and heat transfer coefficient increase. When the volumetric concentration increased to 0.4 , it was observed that the heat transfer coefficient increased by $48 \%$ compared to base fluid water. As mentioned before, the optimum volumetric concentration was found to be $0.392 \%$. The following results are given for optimum volumetric concentration.

In order to show the effects of fin on heat transfer and pressure drop separately; the CFD analysis were also carried out at flow velocities of $1 \mathrm{~m} / \mathrm{s}$ to $7 \mathrm{~m} / \mathrm{s}$ for a straigth (finless) microchannel (Straight MC) having same hydraulic diameter and length. CFD analysis for Straight MC with nanofluid were performed with grid density and convergence criterion similar to the main model.

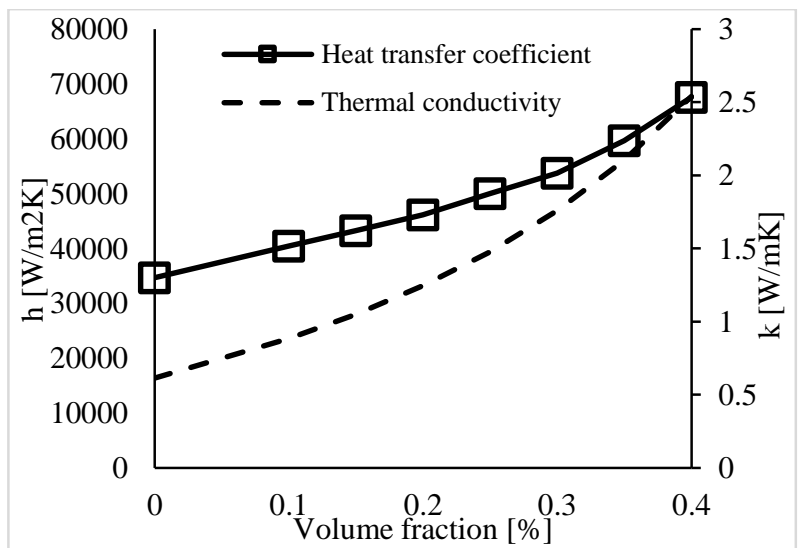

Figure 10. Effect of volume fraction of nanofluids on heat transfer coefficient

The results from the two analysis (for Finned MC and Straight MC) are presented comparatively. Heat transfer coefficients and pressure drop values calculated by CFD analysis are shown in Figs. 11 and 12. As expected, the 
heat transfer coefficients of the Finned MC with nanofluid have been found higher than obtained for Straight MC. Although the analysis have been made under the same boundary conditions, the heat transfer in Finned MC has been better. Because there have been a total of 12 fins in the Finned MC. These fins not only mix the nanofluids flow, but also increase the surface area. Thus, fins have caused to better convective heat transfer. Pressure drop values obtained by analysis in the range of $87<\operatorname{Re}<998$ have been given in Fig. 12. Pressure drop data for Finned MC have exceeded $\Delta \mathrm{P}>50000 \mathrm{~Pa}$ after $\mathrm{Re}>87$ and reached $2 \mathrm{E}+6 \mathrm{~Pa}$. It is not possible to industrialize microchannel heat sinks with these pressure drops. Looking at the pressure drop graph, it has been concluded that a Finned MC can be used as a heat sink, only at low flow velocity $(\mathrm{V}<1 \mathrm{~m} / \mathrm{s})$.

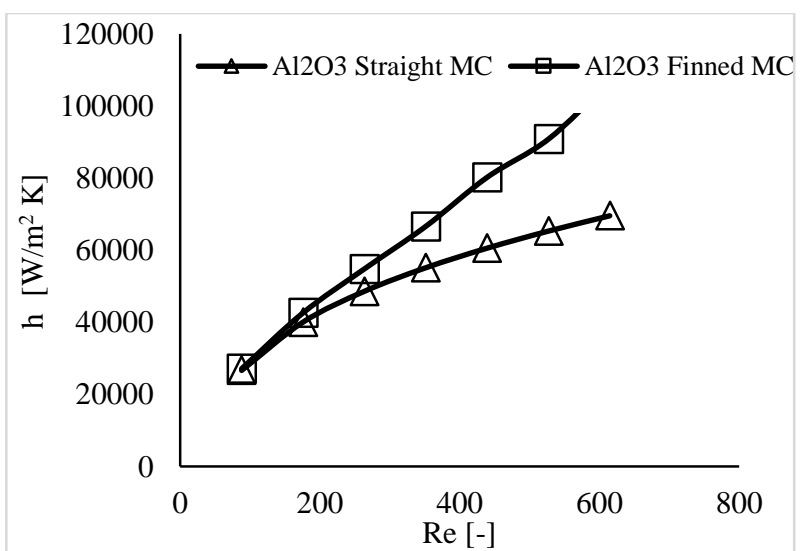

Figure 11. Effect of Reynolds number on heat transfer coefficient

Nusselt and friction factor results of nanofluids flow in Finned and Straigth MC can be seen in Fig. 13. The Nusselts and friction factor values increased with the increase in Reynolds number for Finned and Straigth MC. As seen in the graphic, Nusselts numbers in the case of Finned MC have been found higher than Straigth MC. However, this increase was higher in high Reynolds numbers.

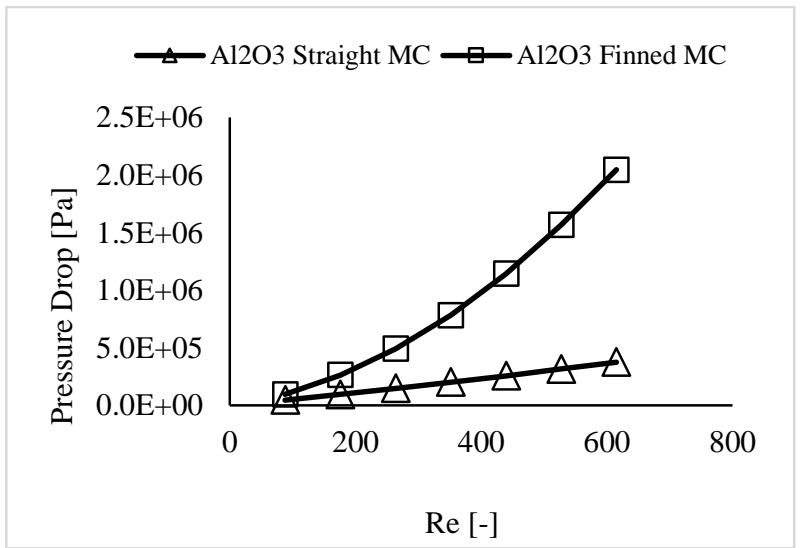

Figure 12. Effect of Reynolds number on pressure drop

The Reynolds number was 615, while the Nusselt number increased by about $40 \%$. In addition, friction coefficient values $[f]$ were lower in Straigth MC, whereas Finned MC was five times higher.

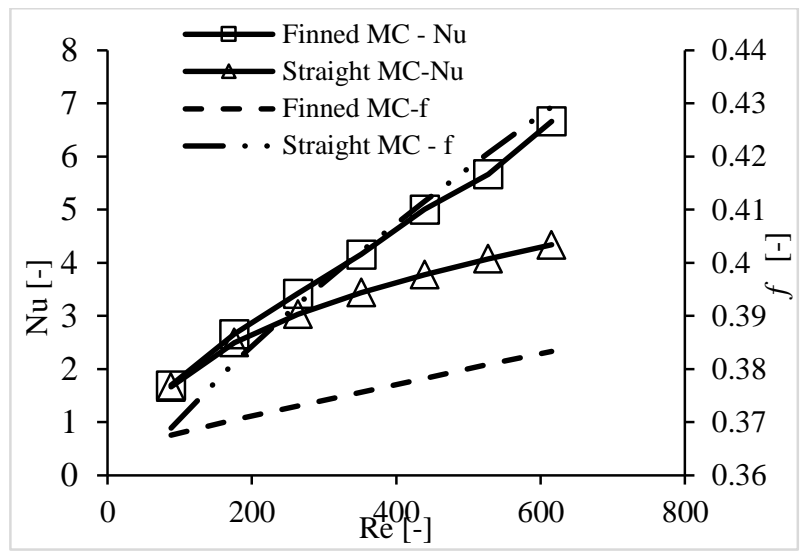

Figure 13. Comparison between the results of straight and finned microchannel

The CFD results also has been compared with existing correlations. Hausen equation (Eq.1) is used for inner fluid flow, at constant surface temperature, hydrodynamically developed and thermally developing flow. Hausen equation is defined as follows (Kaya et al., 2019);

$$
N u=3,66+\frac{0,0668 \operatorname{RePr} \frac{D}{L}}{1+0,04\left(\left(\operatorname{RePr} \frac{D}{L}\right)\right)^{\frac{2}{3}}}
$$

Experimental and numerical studies on different types of nanofluids by (Ambren and Kim, 2018) were reviewed and $N u$ and $f$ correlations published by various researchers in recent years are presented. $\mathrm{Nu}$ correlation of $\mathrm{Al}_{2} \mathrm{O}_{3}$ /water nanofluids at constant wall temperature is presented below (Ambren and Kim, 2018; Maiga et al., 2005).

$N u_{n f}=0.28 R e^{0.35} \operatorname{Pr}^{0.36}$

In the numerical study of (Kaya et al., 2019), the results of the nanofluids flow in the circular microchannel for different nanoparticle volume concentrations were compared with the results obtained from the Hausen equation. Investigation was done under constant laminar flow condition and with different Reynolds numbers $(100<\operatorname{Re}<1000)$ at different nanoparticle volumetric concentrations. Their results showed that the numerical results were compatible with the data obtained from Hausen equation. Pr number in the equation (1) was determined by $\operatorname{Pr}=v_{n f} / \alpha_{n f}$ for optimal volumetric concentration. Other properties of nanofluids were calculated by correlations given in the Table 4 . Calculated Nusselt numbers by Hausen eq. (1) changed from 3.66 to 3.68 and remained almost constant. $\mathrm{Nu}$ numbers calculated by Eq. 2 were found between 2.26 and 3.5 and these values were lower than the CFD results.

Nusselt numbers obtained via CFD changed from 1.66 to 6.66 with increasing Reynolds number. As can be seen in Fig. 14, Nusselt numbers were higher than the data obtained from Hausen equation for Re> 263. Nusselt numbers were found to be lower than those obtained from the Hausen equation for smaller Re numbers. 


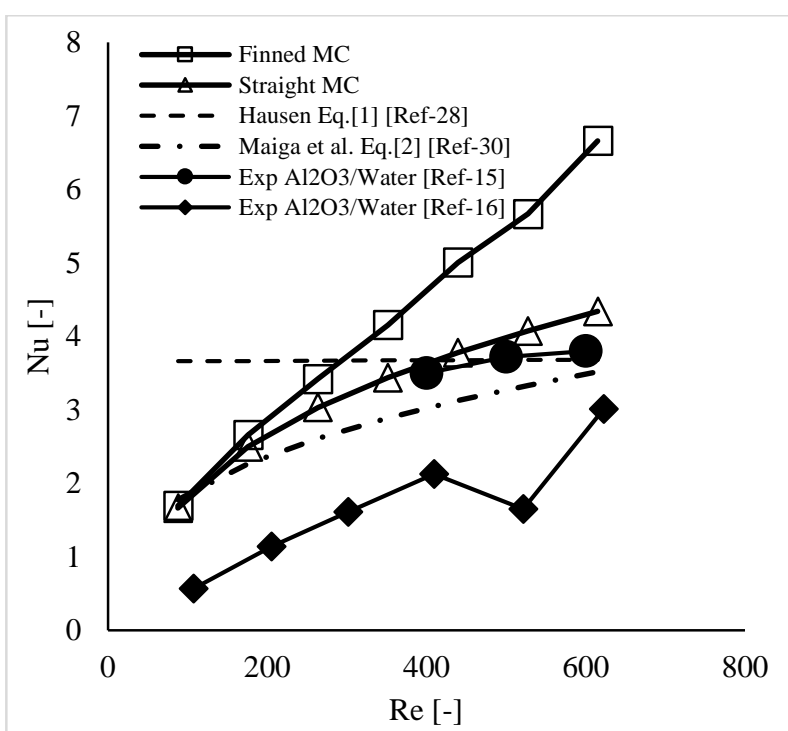

Figure 14. Comparison of Nusselt number between correlations and experimental data for $\mathrm{Al}_{2} \mathrm{O}_{3} /$ water nanofluids.

The closest experimental data to our study in terms of hydraulic diameter and nanofluids type were reported by (Sivakumar et al., 2016) and (Sohel et al., 2014). Experimental results were found to increase with increasing Re numbers. The $\mathrm{Nu}$ numbers reported by (Sivakumar et al., 2016) were found to be lower than the CFD results. On the other hand, experimental data reported by (Sohel et al., 2014) were close to straight microchannel results. Consequently, the experimental data confirm the CFD results.

\section{CONCLUSION}

In this study, 6 pairs of rectangular fins were placed in a single microchannel of rectangular cross-section. Geometry of finned microchannel and the volumetric concentration of nanofluid were optimized with Response Surface Optimization method for the levels of different parameters and CFD simulations for optimal finned microchannel were performed at different flow rates. The results were summarized as follows;

- As a result of the optimization, the optimum fin angle, thickness and length were found as $34^{\circ}, 36.5 \mu \mathrm{m}$ and $50.6 \mu \mathrm{m}$, respectively. Additionally, optimal volumetric concentration of $\mathrm{Al}_{2} \mathrm{O}_{3}$ /water nanofluids was found to be $0.39 \%$.

- The fins caused an increase in the surface area in the microchannel and thus an increase was observed in heat transfer. At the same Reynolds number, pressure drop and heat transfer coefficients in finned microchannel were found higher than in straight microchannel.

- The results also confirmed that the heat transfer coefficient, thermal conductivity, pressure drop increased with an increase in the volume concentration of nanoparticles. It was observed that the pressure drop and heat transfer increased when the inlet flow velocity of nanofluids increased.
- The Nusselt numbers obtained from CFD changed from 1.66 to 6.66 for the range of Reynolds number, $87<\operatorname{Re}<615$. The Nusselt numbers for optimal finned microchannel have been found higher than data from traditional correlation and available experimental results.

- In further studies, it is recommended to investigate the effects of the height and distance of the fins on flow and heat transfer, both experimentally and numerically.

\section{REFERENCES}

DeWitt, D. P., and Incropera, F. P., 2002, Fundamentals of Heat and Mass Transfer, 5th Edition, John Wiley \& Sons, Inc., New York.

Huang, Y.P., Huang, J., Ma, J., Wang, Y.L., and Wang, Q.W., 2010, Experimental investigations on single-phase heat transfer enhancement with longitudinal vortices in narrow rectangular channel, Nuclear Engineering and Design, 240.

Chao Liu, J.T., Chu, Y.L., Chiu, S., Dang, R., Greif, R., Huang, S., Jin, T., Pan, H.H., and Teng, J.C., 2011, Experimental investigations on liquid flow and heat transfer in rectangular microchannel with longitudinal vortex generators, International Journal of Heat and Mass Transfer, 54.

Chen, C., Cheng, C.H., Greif, R., Huang, S., Jin, S., Lee, M.T., Liu, C., Pan, H.H., and Teng, J.T., 2014, A study on fluid flow and heat transfer in rectangular microchannels with various longitudinal vortex generators, International Journal of Heat and Mass Transfer, 69.

Ugurlubilek, N., 2014, Numerical investigation of convective heat transfer and fluid flow in a channel with two semi -circular shaped obstacles, Süleyman Demirel University, Journal of Engineering Sciences and Design 2, 85-89.

Ebrahimi, A., Kheradmand, S. E., and Roohi, 2015, Numerical study of liquid flow and heat transfer in rectangular microchannel with longitudinal vortex generators, Applied Thermal Engineering, 78.

Lelea, D., 2011, The performance evaluation of $\mathrm{Al}_{2} \mathrm{O}_{3}$ /water nanofluid flow and heat transfer in microchannel heat sink, International Journal of Heat and Mass Transfer, 54, 3891-3899.

Chang, C.Y., Hung, T.C., Yan, W.M., and Wang, X.D., 2012, Heat transfer enhancement in microchannel heat sinks using nanofluids, International Journal of Heat and Mass Transfer, 55, 2559-2570.

Lei, J., Liu, Bo., Zhao, J., and Wu, J., 2016, Effectiveness of nanofluid on improving the performance of microchannel heat sink, Applied Thermal Engineering, $101,402-412$. 
Ebrahimi, A., Rikhtegar, F., Roohi, E., and Sabaghan, A., 2016, Heat transfer and entropy generation in a microchannel with longitudinal vortex generators using nanofluids, Energy, 101, 190-201.

Karimzadehkhouei, M., Kosar, A., Menguc, M. P., Sendur, K., and Shojaeian, M., 2017, The effect of nanoparticle type and nanoparticle mass fraction on heat transfer enhancement in pool boiling, International Journal of Heat and Mass Transfer, 109, 157-166.

Ding, G., Hu, H., Jiang, W., and Peng, H., 2011, Effect of nanoparticle size on nucleate pool boiling heat transfer of refrigerant/oil mixture with nanoparticles, International Journal of Heat and Mass Transfer, 54, 910, 1839-1850.

Karimipour, A., Toghraie, D., and Zarringhalam, M., 2016, Experimental study of the effect of solid volume fraction and Reynolds number on heat transfer coefficient and pressure drop of $\mathrm{CuO} /$ Water nanofluid, Experimental Thermal and Fluid Science, 76, 342-351.

Khaleduzzaman, S.S., Mahbubul, I.M., Niza, M.E., Saidur, R., Selvaraj, J., Sohel, M.R., and Ward, T.A., 2017, Experimental analysis of energy and friction factor for titanium dioxide nanofluid in a water block heat sink, International Journal of Heat and Mass Transfer, 115, $77-85$.

Hepbasli, A., Khaleduzzaman, S.S., Mahbubul, I.M., Sabri, M. F. M., Saidur, R., and Sohel, M.R., 2014, An experimental investigation of heat transfer enhancement of a minichannel heat sink using $\mathrm{Al}_{2} \mathrm{O}_{3} / \mathrm{H}_{2} \mathrm{O}$ nanofluid, International Journal of Heat and Mass Transfer, 74, 164-172.

Alagumurthi, N., Senthilvelan, T., and Sivakumar, A. 2016, Experimental investigation of forced convective heat transfer performance in nanofluids of $\mathrm{Al}_{2} \mathrm{O}_{3}$ /water and $\mathrm{CuO} /$ water in a serpentine shaped micro channel heat sink, Heat Mass Transfer, 52, 1265-1274.

Amanid, M., Ho, C.J., Liaoa, J.C., Lib, C.H., and Yan, W.M., 2019, Experimental study of cooling characteristics of water-based alumina nanofluid in a minichannel heat sink, Case Studies in Thermal Engineering, 14, 100418.

Liang, G., and Mudawar, I., 2019, Review of singlephase and two-phase nanofluid heat transfer in macrochannels and micro-channels, International Journal of Heat and Mass Transfer, 136, 324-354.

Arshi Banu, P.S., Krishnan, A., Sagaya Raj, A.G., and Shafee, S.M., 2020, Numerical investigation of micropin-fin heat exchanger using nanofluids, Materials Today: Proceedings, 22, 1020-1025.
Bahiraei, M., Hosseini, Y., Mazaheri, N., and Moayedi, H., 2019, A two-phase simulation for analyzing thermohydraulic performance of $\mathrm{Cu} /$ water nanofluid within a square channel enhanced with $90 \_$V-shaped ribs, International Journal of Heat and Mass Transfer, 145,118612

Kim, M.H., and Saeed, M., 2018, Heat transfer enhancement using nanofluids $\left(\mathrm{Al}_{2} \mathrm{O}_{3} / \mathrm{H}_{2} \mathrm{O}\right)$ in minichannel heatsinks, International Journal of Heat and Mass Transfer, 120, 671-682.

Ghasemi, S. E., Hosseini, M.J., and Ranjbar, A.A., 2017, Forced convective heat transfer of nanofluid as a coolant flowing through a heat sink: Experimental and numerical study, Journal of Molecular Liquids, 248, 264-270.

Turkyilmazoglu, M., 2019, Fully developed slip flow in a concentric annuli via single and dual phase nanofluids models, Computer Methods and Programs in Biomedicine, 179, 104997.

Cho, Y. I., and Pak, B.C., 1998, Hydrodynamic and heat transfer study of dispersed fluids with submicron metalic oxide particles, Experimental Heat Transfer An International Journal, 11:2, 151-170.

Roetzel, W., and Xuan, Y., 2000, Conceptions for heat transfer correlation of nanofuids, International Journal of Heat and Mass Transfer, 43, 3701土3707.

Choi, S.U.S., and Yu, W., 2003, The role of interfacial layers in the enhanced thermal conductivity of nanofluids: A renovated Maxwell model, Journal of Nanoparticle Research, 5, 167-171.

Brinkman, H.C., 1952, The Viscosity of Concentrated Suspensions and Solutions, The Journal of Chemical Physics, Volume 20, Number 4, Pg.571.

Arslan, K., Ekiciler, R., and Kaya, H., 2019, CFD analysis of laminar forced convective heat transfer for $\mathrm{TiO}_{2} /$ Water nanofluid in sem1 circular cross sectioned microchannel, Journal of Thermal Engineering, 5, 123137.

Ambreen, T., and Kim, M.H., 2018, Heat transfer and pressure drop correlations of nanofluids: A state of art review, Renewable and Sustainable Energy Reviews, 91, 564-583.

Galanis, N., Maiga, S. E. B., Nguyen, C. T., Palm, S.J., and Roy, G., 2005, Heat transfer enhancement by using nanofluids in forced convection flows, International Journal of Heat and Fluid Flow, 26, 530-546. 

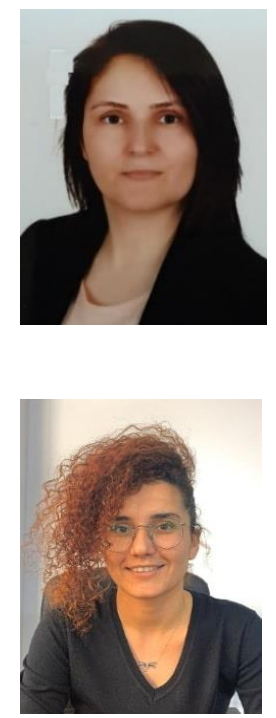

Nezaket Parlak is an Associate Professor in Mechanical Engineering Department at Sakarya University (SAU), Turkey. She graduated from University of Trakya in 2000 with a BSME Degree. She received an MSc (2003) and a PhD (2010) in Mechanical Engineering from Sakarya University. Her PhD concerned experimental and theoretical analysis of laminar single-phase fluid flow and heat transfer in microchannels. Between 2005 and 2006, she worked as a visiting student on Stirling engines at Regensburg University of Applied Sciences, Germany. Her field of interest includes single and two phase fluid flow and heat transfer, nanofluids, heat transfer enhancement techniques, drying agricultural products and renewable energy applications.

Halime Çelik, received his B.Sc. and M.Sc. degree in Mechanical Engineering from Sakarya University in 2016 and 2019, respectively. In her master's thesis, she worked on CFD modeling of nanofluids passing through microchannel. Her field of interest includes micro-scale devices and manufacturing techniques, heat recovery methods, renewable energy sources. 